\title{
The differential distribution of bacteria between cancerous and noncancerous ovarian tissues in situ
}

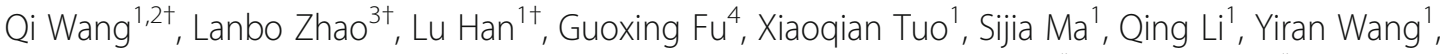 \\ Dongxin Liang ${ }^{1}$, Miaomiao Tang ${ }^{1}$, Chao Sun ${ }^{1}$, Qing Wang ${ }^{1}$, Qing Song ${ }^{1,5^{*}}$ and Qiling Li ${ }^{1 *}$ (D)
}

\begin{abstract}
Background: With the improvement of bacterial detection, the theory of the sterile female upper reproductive tract has been frequently challenged in recent years. However, thus far, no researchers have used ovaries as study targets.
\end{abstract}

Methods: Six women who were diagnosed with ovarian cancer were included in the cancer group, and ten women who were diagnosed with a noncancerous ovarian condition (including three patients with uterine myoma and seven patients with uterine adenomyosis) were included in the control group. Immunohistochemistry staining using an antibacterial lipopolysaccharide (LPS) antibody was used to confirm the presence of bacteria in the ovarian tissues. In addition, 16S rRNA sequencing was used to compare the differences in the bacteria between ovarian cancer tissues and noncancerous ovarian tissues. BugBase and Phylogenetic Investigation of Communities by Reconstruction of Unobserved States (PICRUSt) were used to predict the functional composition of the bacteria.

Results: Bacterial LPS was present in ovarian cancer tissue and noncancerous ovarian tissue, which implied the presence of bacteria in ovarian tissue. When compared to the noncancerous ovarian bacteria at the phylum level, the cancerous ovarian bacteria were composed of increased Aquificae and Planctomycetes and decreased Crenarchaeota. When predicting metagenomes, gene functions associated with the potentially pathogenic and the oxidative stress-tolerant phenotype were enriched in the ovaries of the cancer group. Forty-six significantly different KEGG pathways existed in the ovarian bacteria of the cancer group compared to that of the control group.

Conclusions: Different bacteria compositions were present in cancerous and noncancerous ovarian tissues.

Trial registration: Chines Clinical Trail Registry, CHiCTR1800020018, Registered 11 September 2018, http://www. chictr.org.cn/

Keywords: Ovarian cancer, Bacteria, 16S rRNA sequencing, Lipopolysaccharide, KEGG

\section{Introduction}

Abdominal solid viscera, including the pancreas, kidney, spleen, liver and ovary, have always been believed to be absolutely sterile. However, this concept is being challenged. Leore et al. found that the bacteria in pancreatic tumors could mediate tumor resistance to the chemotherapeutic drug gemcitabine [1]. S.

\footnotetext{
* Correspondence: qsong@msm.edu; Liqiling@mail.xjtu.edu.cn

${ }^{\dagger}$ Qi Wang, Lanbo Zhao and Lu Han contributed equally to this work.

'Department of Obstetrics and Gynecology, First Affiliated Hospital, Xi'an

Jiaotong University, Xi'an, Shaanxi, China

Full list of author information is available at the end of the article
}

Manfredo Vieira et al. confirmed that Enterococcus gallinarum can translocate to the lymph nodes, liver and spleen and drive autoimmunity [2].

The upper female reproductive tract, including the uterus, fallopian tubes and ovaries, has been believed to be absolutely sterile due to the obstacle of the cervix, which is also being challenged. The change in mucins in the cervix during the menstrual cycle may lead to the passage of bacteria [3, 4]. In addition, research has confirmed that the uterus and fallopian tubes represent a functionally united peristaltic pump under the endocrine

(c) The Author(s). 2020 Open Access This article is distributed under the terms of the Creative Commons Attribution 4.0 International License (http://creativecommons.org/licenses/by/4.0/), which permits unrestricted use, distribution, and reproduction in any medium, provided you give appropriate credit to the original author(s) and the source, provide a link to the Creative Commons license, and indicate if changes were made. The Creative Commons Public Domain Dedication waiver (http://creativecommons.org/publicdomain/zero/1.0/) applies to the data made available in this article, unless otherwise stated. 
control of the ovaries [5], which may aid the bacteria to enter the endometrium, fallopian tubes, and ovaries.

With the improvement of bacterial detection, researchers have been investigating the upper reproductive tract. Verstraelen et al. aimed to explore the presence of a uterine bacteria using a barcoded Illumina paired-end sequencing method targeting the V1-2 hypervariable region of the 16S RNA gene [6]. Fang et al. revealed diverse intrauterine bacteria in patients with endometrial polyps using barcoded sequencing [7]. Miles and Chen also investigated the bacteria of the reproductive tract in women undergoing hysterectomy and salpingo-oophorectomy using the 16S RNA gene [4, 8]. However, all the abovementioned researchers used endometrial diseases as their research targets, so the question of whether the ovaries are sterile is still unclear.

In recent years, the bacteria of tumor tissues have become a hot topic for researchers. Aleksandar et al. confirmed that Fusobacterium was enriched in colorectal tumors [9]. In addition, Bullman et al. discovered that the colonization of human colorectal cancers with Fusobacterium is maintained in distal metastases and bacteria stability between paired primary and metastatic tumors [10]. Bacteria-driven or-associated carcinogenesis has been demonstrated not only in CRC but also in the cancers of stomach, lung, prostate, breast, cervix and endometrium [11-15]. However, whether the bacteria in ovarian tissue are associated with ovarian cancer was still a question. Therefore, in this study we compared compositional and functional differences of bacteria in cancerous ovarian tissue and normal ovaries.

In this study, we used immunohistochemistry staining and $16 \mathrm{~S}$ rRNA sequencing to confirm the presence of bacteria in the ovaries. First, we compared the differences in the ovarian bacteria and its predicted function between cancerous and noncancerous ovarian tissues.

\section{Material and methods Patient characteristics}

Sixteen patients were enrolled at the First Affiliated Hospital of Xi'an Jiaotong University. Patients with following criteria were included in cancer group: patient with a preliminary diagnosis of suspected ovarian cancer and undergoing laparotomy, and the pathology was serous ovarian cancer. Patients with following criteria were included in control group: patients with a preliminary diagnosis of uterine myoma or uterine adenomyosis and undergoing hysterectomy and salpingooophorectomy. The exclusion criteria were as follows: patients who were pregnant or nursing, patients who used antibiotics within 2 months before surgery, patients who had a fever or elevated inflammatory markers, patients with any types of inflammation, and patients with neoadjuvant chemotherapy.

\section{Sample collection}

Once removed, the ovaries were cut into approximately 1-cm thick ovarian tissue samples using a pair of sterile new tweezers without touching anything else. Then, the collected sample was placed into a sterile tube and placed in liquid nitrogen. Specimens were then transferred to the laboratory and stored at $-80^{\circ} \mathrm{C}$.

\section{Immunohistochemistry for bacterial lipopolysaccharide (LPS) in ovaries}

Immunohistochemistry staining was performed on $5 \mu \mathrm{m}$ serial sections from routine formalin-fixed, paraffinembedded (FFPE) tissues. The samples were deparaffinized and rehydrated, and antigen retrieval was performed by microwave treatment for $10 \mathrm{~min}$ in EDTA buffer $(\mathrm{pH}$ 9.0). Endogenous peroxidase activity was stopped by incubating samples with $0.3 \%$ hydrogen peroxide in PBS for 20 min. A DAB substrate kit was used to detect HRP (Zytomed Systems, Berlin, Germany). A ZytoChem Plus HRP Polymer Anti-Rabbit secondary antibody was used according to the manufacturer's instructions (Zytomed Systems). To find the bacteria, the antibody to LPS core (Hycult Biotech, Uden, Netherlands; Clone WN1 222-5) was used at a concentration of 1:300 overnight at $4{ }^{\circ} \mathrm{C}$.

\section{S rRNA sequencing}

DNA extractions were performed by using the Mag-Bind ${ }^{\circ}$ Pathogen DNA 96 Kit (Omega Biotek, Norcross, USA). DNA was quantified using the QuantiFluor dsDNA System (Promega, Madison, USA). The libraries were prepared using an Illumina 16S Metagenomic Sequencing kit (Illumina, Inc., San Diego, USA) according to the manufacturer's protocol. The V3-V4 region of the bacterial $16 \mathrm{~S}$ rRNA gene sequences was amplified using the primer pair containing the gene-specific sequences and Illumina adapter overhang nucleotide sequences. The full-length primer sequences were as follows: $16 \mathrm{~S}$ Amplicon PCR Forward primer: 5' TCGTCGGCAGCGTCAGATGTGT ATAAGA GACAG-[CCTACGGGNGGCWGCAG] and 16S Amplicon PCR Reverse primer: 5' GTCTCGTGGG CTCGGAGATGTGTATAAGAGACAG-[GACT ACHVGGGTATCTAATCC].

Amplicon polymerase chain reaction (PCR) was performed to amplify the template from the DNA sample input. Briefly, each $25 \mu \mathrm{L}$ PCR contained $12.5 \mathrm{ng}$ of sample DNA as an input, $12.5 \mu \mathrm{L}$ of 2x KAPA HiFi HotStart ReadyMix (Kapa Biosystems, Wilmington, USA) and $5 \mu \mathrm{L}$ of $1 \mu \mathrm{M}$ of each primer. PCRs were carried out using the following protocol: an initial denaturation step was performed at $95^{\circ} \mathrm{C}$ for $3 \mathrm{~min}$ followed by 25 cycles of denaturation $\left(95^{\circ} \mathrm{C}, 30 \mathrm{~s}\right)$, annealing $\left(55^{\circ} \mathrm{C}, 30 \mathrm{~s}\right)$ and extension $\left(72^{\circ} \mathrm{C}, 30 \mathrm{~s}\right)$, and a final elongation for $5 \mathrm{~min}$ at $72{ }^{\circ} \mathrm{C}$. The reaction mix was removed from the PCR 
product with Mag-Bind RxnPure Plus magnetic beads (Omega Biotek).

A second index PCR amplification, used to incorporate the barcodes and sequencing adapters into the final PCR product, was performed in $25 \mu \mathrm{L}$ reactions using the same master mix conditions as described above. The cycling conditions were as follows: $95^{\circ} \mathrm{C}$ for $3 \mathrm{~min}$, followed by 8 cycles of $95^{\circ} \mathrm{C}$ for $30 \mathrm{~min}, 55^{\circ} \mathrm{C}$ for $30 \mathrm{~min}$ and $72{ }^{\circ} \mathrm{C}$ for $30 \mathrm{~min}$. A final 5-min elongation step was performed at $72^{\circ} \mathrm{C}$.

The library was checked using an Agilent 2200 TapeStation and quantified using a QuantiFluor dsDNA System (Promega). Libraries were then normalized, pooled and sequenced $(2 \times 300 \mathrm{bp}$ paired-end read setting) on the MiSeq (Illumina, San Diego, USA) using a 600 cycle V3 standard flowcell producing approximately 100,000 paired-end $2 \times 300$ base reads (Omega Bioservices, Norcross, USA).

\section{S rRNA sequencing analysis}

For each sample, the raw reads were filtered based on sequencing quality using Trimmomatic [16]. The primer and adaptor sequences were removed. Sequence reads with both pair-end qualities lower than 25 were truncated. The software package QIIME was used to perform the $16 \mathrm{~S}$ rRNA analyses. Sequences were clustered into operational taxonomic units (OTUs) at a $97 \%$ similarity cutoff, and the relative abundance was calculated for the OTUs in each sample. All sequences were classified using a native Bayesian classifier trained against the RDP training set (version 9; http://sourceforge.net/projects/ rdp-classifier/), and OTUs were assigned a classification based on which taxonomy had the majority consensus of the sequences within a given OTU. The OTUs were then aligned to the Silva database. Alpha diversity (including the Chao 1 index, the ACE index, the Shannon index, the Simpson index and the Evenness index) and the UniFrac-based principal coordinates analysis (PCoA) were performed based on the sample group information.

\section{The prediction of bacteria function}

The relative representation of the bacteria characteristics was predicted using BugBase on the basis of six phenotype categories (Ward et al. unpublished) (https://bugbase.cs. umn.edu/): Gram staining, oxygen tolerance, ability to form biofilms, mobile element content, pathogenicity, and oxidative stress tolerance. This software balances the Kyoto Encyclopedia of Genes and Genomes (KEGG) database, the Integrated Microbial Genomes (IMG4) platform and the Pathosystems Resource Integration Center (PATRIC) system to confirm the contribution of specific OTUs to a community-level phenotype [17-19]. PICRUSt was used to predict the functional composition of a metagenome using marker gene data and a database of reference genomes.
Functional differences among the different groups were compared using STAMP software [20, 21].

\section{Statistics}

Analyses were performed in SPSS unless stated above. $P<$ 0.05 was considered an indication of statistical significance. The differences in age and parity of patients were assessed with the use of Student's t-test. The differences in menopausal status, history of hypertension and diabetes were assessed using the chi-square test. Differences in the number of ovarian bacteria taxa were assessed with the use of the Mann-Whitney U test.

\section{Results}

\section{Participant patients}

Sixteen patients who were undergoing oophorectomy or hysterectomy and salpingo-oophorectomy were included in this study. In this study, ten women who were diagnosed with benign endometrial conditions with noncancerous ovaries (including three patients with uterine myoma and seven patients with uterine adenomyosis) were set as the control group, and six women who were diagnosed with ovarian cancer (including two patients who were diagnosed in stage II and four patients who were diagnosed in stage $\amalg$ ) were set as the cancer group. All diagnoses were based on final surgical pathology after oophorectomy or hysterectomy and salpingooophorectomy. Compared with the control group, the age, menopausal status, parity, history of hypertension and history of diabetes in patients diagnosed with ovarian cancer were not significantly different (Table 1).

\section{The presence of bacteria in the ovaries}

To confirm the presence of bacteria in ovaries using nonPCR-based methods, we performed immunohistochemistry staining using an antibacterial LPS antibody. The results showed that bacterial LPS were present in the cancerous ovarian tissue and noncancerous ovarian tissue, which implied the presence of bacteria in ovarian tissue (Fig. 1).

\section{Ovarian bacterial richness and diversity between cancer and control groups}

To detect the ovarian bacterial species richness and diversity between the two groups, we analyzed the alpha diversity of the microbes. The observed number of species in the ovarian cancer tissues was lower than that in the ovaries of the control group, but the difference was not significant. Moreover, we found that not only the bacterial species richness (represented by the Chao 1 index and the ACE index) but also the diversity (represented by the Shannon Index, the Simpson Index, and the Evenness Index) in the ovarian cancer group were not significantly different from those in the control group (Fig. 2). 
Table 1 Clinical characteristics of patients enrolled in the study

\begin{tabular}{|c|c|c|c|}
\hline & Control group $(n=10)$ & Cancer group $(n=6)$ & $P$ value \\
\hline Age & $51.6(45-57)$ & $57.3(46-75)$ & 0.29 \\
\hline Menopausal status & & & 0.12 \\
\hline Pre/Peri & 8 & 2 & \\
\hline Post & 2 & 4 & \\
\hline Parity & $5.1(1-13)$ & $3.1(2-5)$ & 0.17 \\
\hline History of hypertension & & & 0.52 \\
\hline Yes & 1 & 2 & \\
\hline NO & 9 & 4 & \\
\hline History of diabetes & & & 0.70 \\
\hline Yes & 1 & 1 & \\
\hline NO & 9 & 5 & \\
\hline \multicolumn{4}{|l|}{ Stage (\%) } \\
\hline$\|$ & & 2(33.3) & \\
\hline III & & $4(66.7)$ & \\
\hline \multicolumn{4}{|l|}{ Histotype (\%) } \\
\hline Uterine myoma & $3(30)$ & - & \\
\hline Uterine adenomyosis & $7(70)$ & - & \\
\hline Ovarian serous carcinoma & - & $6(100)$ & \\
\hline
\end{tabular}

The $P$-value of age and parity were assessed by Student's t-test. The $P$-value of menopausal status, history of hypertension and diabetes were calculated by the chi-square test

\section{Ovarian bacteria characterization between cancer and control groups}

To understand the ovarian bacteria in cancer and control groups, we performed deep sequencing of the V3V4 16S rRNA region of all sixteen collected samples. In the ovaries, our results showed that Proteobacteria was the most abundant phylum $(67.1 \%$ in the control group and $67.20 \%$ in the cancer group). Firmicutes was the second most abundant phylum $(23.77 \%$ in the control group and $23.82 \%$ in the cancer group), and the third most abundant phylum was Bacteroidetes $(3.26 \%$ in the control group and $3.41 \%$ in the cancer group) (Fig. 2a,
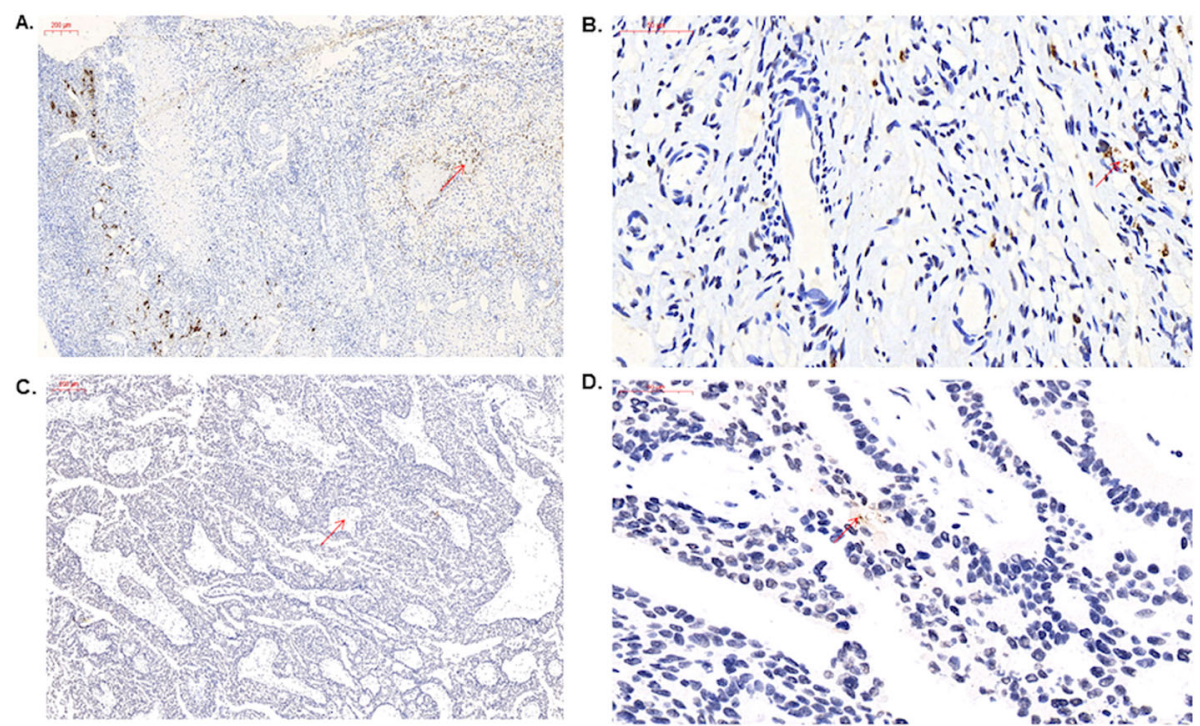

Fig. 1 BugBase analysis of predicted metagenomes. The potentially pathogenic and immunohistochemistry of ovaries using an antibacterial LPS antibody. a control group (10x). Scale bars, $200 \mu \mathrm{m}$. b control group (40x). Scale bars, $50 \mu \mathrm{m}$. c cancer group (10x). Scale bars, $200 \mu \mathrm{m}$. d cancer group (40x). Scale bars, $50 \mu \mathrm{m}$. Arrows point to LPS staining in the ovarian tissue 


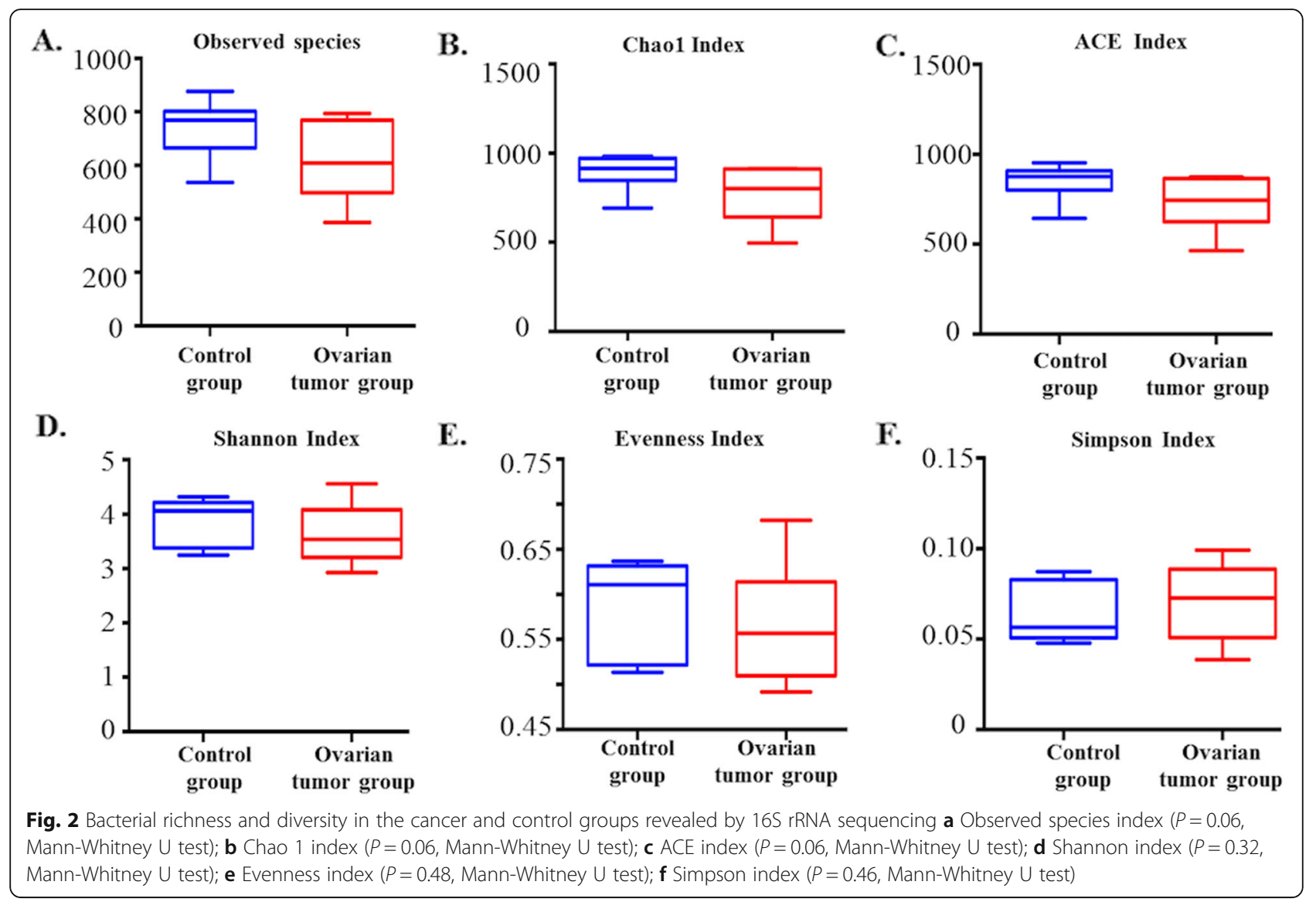

b). At the species level, the ovarian bacterial communities were dominated by Halobacteroides halobius (14.53\%), followed by Gemmata obscuriglobus (11.07\%) and Methyloprofundus sedimenti (10.69\%) in the control group. The ovarian bacterial communities in the cancer group were dominated by Gemmata obscuriglobus (13.89\%), followed by Halobacteroides halobius (11.99\%) and Methyloprofundus sedimenti (11.12\%) (Fig. 3).

\section{Ovarian bacterial community composition differences between cancer and control groups}

We carried out a comparison of differences in the overall bacterial communities using PCoA, which showed that the ovarian bacteria of the control group displayed some differences compared to that of the cancer group (Fig. 4a and b).

\section{Ovarian bacterial composition at different levels in cancer and control groups}

To detect the differences in ovarian bacteria between the seventeen samples, we analyzed the ovarian bacterial composition at different levels in cancer and control groups. In the Table 2, we showed the statistical difference of ovarian bacteria in cancer and control groups at phylum, class, order, family, genus and species level. In particular, the relative abundance of Anoxynatronum sibiricum may be associated with the stage of the tumor (Fig. 4c), and Methanosarcina vacuolata may be used to diagnose ovarian cancer (Fig. 4d).

\section{Predicted function of the ovarian bacteria shows phenotypic conservation between cancer and control groups}

BugBase identified that gene functions associated with the potentially pathogenic and the oxidative stresstolerant phenotype were enriched in the ovaries of the cancer group (Wilcoxon signed-rank test, $P=0.02$ and $P=0.002$ ). The aerobic, anaerobic, facultatively anaerobic, gram-positive, and gram-negative phenotypes; mobile elements; and biofilm formation of the ovarian bacteria showed no significant difference between ovarian cancer and control groups (Fig. 5). PICRUSt was used to identify the KEGG pathways between the bacteria of ovaries in cancer and control groups and found 46 different KEGG pathways. The ovaries in the cancer group showed increased pathways related to streptomycin biosynthesis, carbon fixation in photosynthetic organisms, glycosphingolipid biosynthesis-globo series, cyanoamino acid metabolism, glycerophospholipid metabolism, butirosin and neomycin biosynthesis, other 


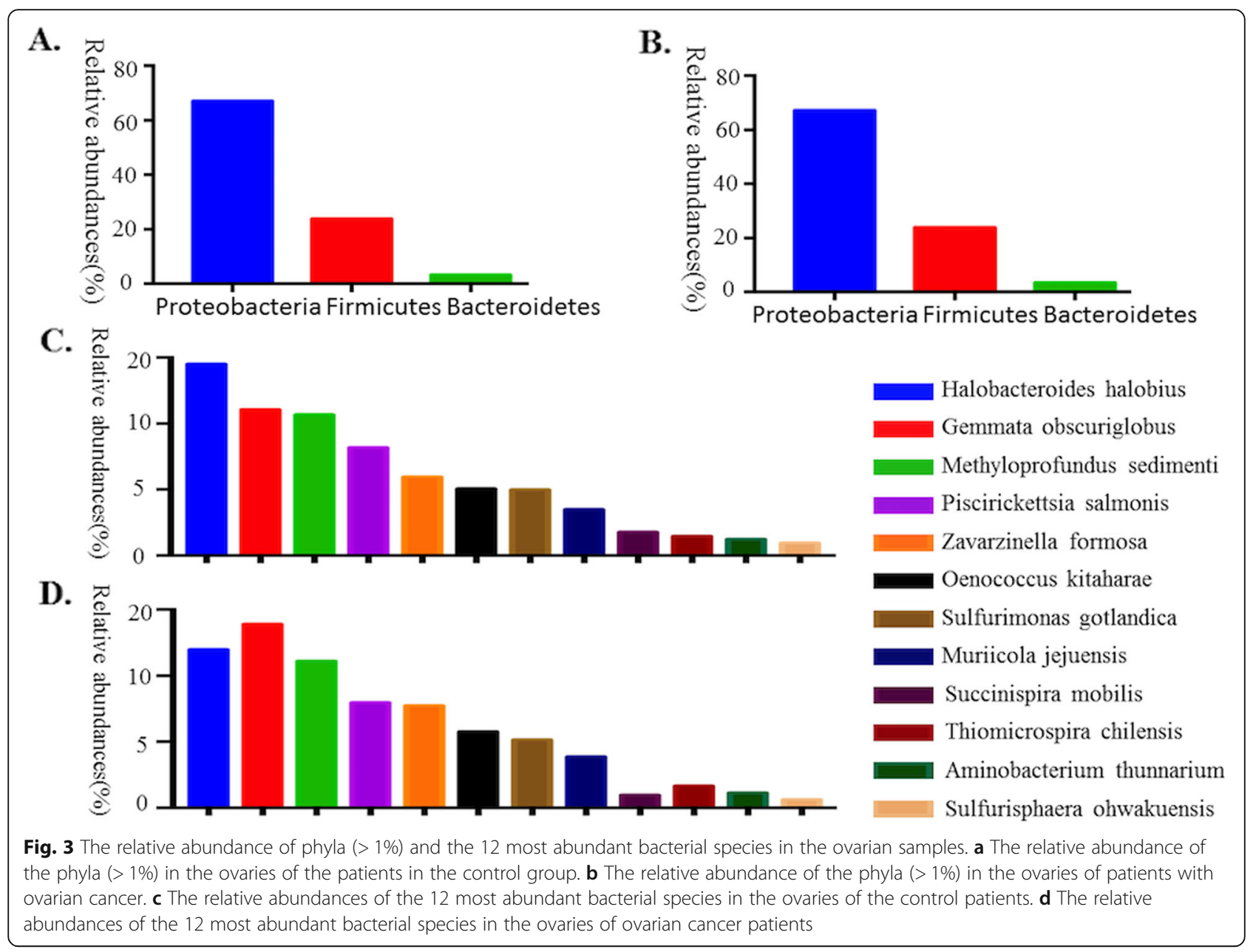

glycan degradation, biosynthesis of vancomycin group antibiotics, polyketide sugar unit biosynthesis, the pentose phosphate pathway, transporters, tuberculosis, starch and sucrose metabolism, fructose and mannose metabolism, phenylalanine metabolism, lysosomes, glycosaminoglycan degradation, pentose and glucuronate interconversions, pyruvate metabolism, amino sugar and nucleotide sugar metabolism, galactose metabolism, biosynthesis of ansamycins, methane metabolism, membrane and intracellular structural molecules, metabolism of cofactors and vitamins, glutamatergic synapse, and the cell cycle. However, the bacteria in ovarian cancer tissue showed reduced alpha-linolenic acid metabolism, biosynthesis of unsaturated fatty acids, bacterial secretion system, proximal tubule bicarbonate reclamation, prion diseases, secretion system, carbon fixation pathways in prokaryotes, unknown functions, other ion-coupled transporters, sulfur metabolism, biotin metabolism, protein kinases, ubiquinone and other terpenoid-quinone biosynthesis, two-component system, folate biosynthesis, cell motility and secretion, citrate cycle (TCA cycle) and ribosome biogenesis in eukaryotes (Fig. 6).

\section{Discussion}

Ovarian cancer is the seventh most commonly diagnosed cancer among women that could affect fertility [22]. Most ovarian cancer patients are diagnosed at stages III and IV, and the 5-year survival rate is less than 30\% [23]. Researchers have confirmed that the abdominal solid viscera, including the liver, pancreas and spleen, are not absolutely sterile, and the bacteria exist in the upper female reproductive tract as a result of leakage from the cervix $[1,4]$. However, the ovaries are still not a research target. The question remains unanswered that whether the ovaries, as one of the abdominal solid viscera, have a bacterium and whether the bacteria has an association with ovarian cancer.

In this study, we first confirmed the presence of bacteria in the ovaries. In addition, we detected significant differences in the ovarian bacteria of patients with 


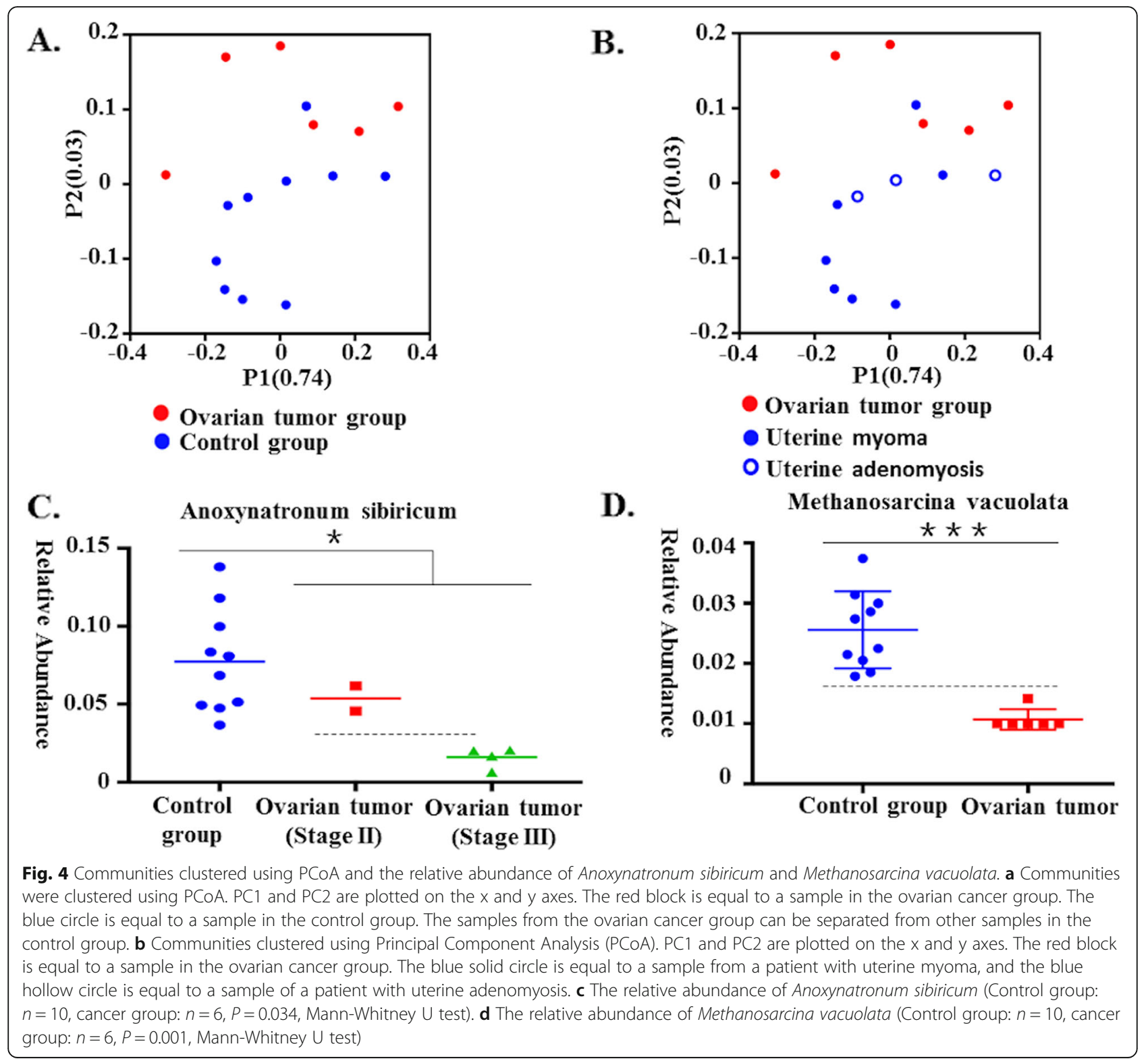

ovarian cancer when compared with samples from noncancerous women.

To avoid bacterial contamination, all instruments used were sterilized, and the reagent we used was new. When operating, the surgeon wore an autoclaved mask, cap and suit and did not talk. The sample did not touch anything in the operating room except for the tweezers and was immediately put into the sterilized tube. When the sample was transferred to the laboratory, as many of the procedures as possible were performed on the asepsis work table except the procedures that required large equipment, such as centrifugal machines and sequencers. More importantly, we used ovaries from patients with benign uterine disease as the control group to counteract possible contamination.
There are three possible reasons to explain the origination of the ovarian bacteria. First, a new opinion is that the upper female reproductive tract is not sterile [4], and different bacteria exist throughout the female reproductive tract, forming a continuum from the vagina to the ovaries [23]. The bacteria in the ovaries may originate from the fallopian tubes, uterine cavity, cervix canal or vagina, which is in contact with the outside environment. Besides, many researches have confirmed tubal ligation decreases the risk of EOC by unknown mechanisms [24, 25]. Walther et al. were able to amplify bacterial DNA from $94 \%$ of the cervical/vaginal samples and $87 \%$ of the uterine samples [23]. However, they were only able to amplify bacterial DNA from 50 and $61 \%$ of fallopian tubes and ovaries, which imply the potential 
Table 2 Differential relative abundance of the taxa in ovarian communities between patients in cancer and control group

\begin{tabular}{|c|c|c|c|c|}
\hline & & Control cohort $(n=10, \%)$ & Ovarian tumor cohort $(n=6, \%)$ & $P$ value \\
\hline \multirow[t]{3}{*}{ Phylum } & Planctomycetes & $0.5144 \pm 0.1420$ & $0.8655 \pm 0.2638$ & 0.023 \\
\hline & Crenarchaeota & $0.2840 \pm 0.0787$ & $0.1592 \pm 0.0775$ & 0.023 \\
\hline & Aquificae & $0.0352 \pm 0.0137$ & $0.0697 \pm 0.0291$ & 0.017 \\
\hline \multirow[t]{2}{*}{ Class } & Spartobacteria & $0.3149 \pm 0.0923$ & $0.4795 \pm 0.1205$ & 0.026 \\
\hline & Sphingobacteriia & $0.1280 \pm 0.0695$ & $0.0423 \pm 0.0706$ & 0.039 \\
\hline \multirow[t]{6}{*}{ Order } & Planctomycetales & $7.2700 \pm 1.3880$ & $9.1183 \pm 0.8594$ & 0.039 \\
\hline & Pseudomonadales & $0.1332 \pm 0.0746$ & $0.4283 \pm 0.4019$ & 0.023 \\
\hline & Enterobacteriales & $0.6038 \pm 0.1237$ & $2.0105 \pm 2.5829$ & 0.030 \\
\hline & Methanobacteriales & $0.1626 \pm 0.0496$ & $0.2602 \pm 0.0859$ & 0.030 \\
\hline & Halobacteriales & $0.0648 \pm 0.0117$ & $0.0439 \pm 0.0287$ & 0.039 \\
\hline & Campylobacterales & $0.0776 \pm 0.0158$ & $0.1133 \pm 0.0232$ & 0.009 \\
\hline \multirow[t]{12}{*}{ Family } & Flavobacteriaceae & $24.7500 \pm 0.6712$ & $21.7167 \pm 3.0732$ & 0.014 \\
\hline & Methanobacteriaceae & $0.1720 \pm 0.0540$ & $0.2667 \pm 0.0867$ & 0.039 \\
\hline & Moraxellaceae & $0.1328 \pm 0.0658$ & $0.4347 \pm 0.4054$ & 0.030 \\
\hline & Petrotogaceae & $0.0452 \pm 0.0178$ & $0.0638 \pm 0.0112$ & 0.039 \\
\hline & Thermaceae & $0.0078 \pm 0.0089$ & $0.0188 \pm 0.0086$ & 0.017 \\
\hline & Archaeoglobaceae & $0.0611 \pm 0.0221$ & $0.0381 \pm 0.0123$ & 0.045 \\
\hline & Leptotrichiaceae & $0.1018 \pm 0.0524$ & $0.0442 \pm 0.0284$ & 0.030 \\
\hline & Microbacteriaceae & $0.1493 \pm 0.0618$ & $0.2740 \pm 0.1320$ & 0.039 \\
\hline & Staphylococcaceae & $0.0281 \pm 0.0545$ & $0.0822 \pm 0.0536$ & 0.029 \\
\hline & Thermogemmatisporaceae & $0.7381 \pm 0.1925$ & $1.4583 \pm 0.6982$ & 0.013 \\
\hline & Methanocorpusculaceae & $0.0233 \pm 0.0139$ & $0.0091 \pm 0.0063$ & 0.023 \\
\hline & Geodermatophilaceae & $0.0552 \pm 0.0335$ & $0.0144 \pm 0.0145$ & 0.030 \\
\hline \multirow[t]{10}{*}{ Genus } & Paenibacillus & $0.7990 \pm 0.4563$ & $0.3207 \pm 0.2151$ & 0.039 \\
\hline & Haloferula & $0.1811 \pm 0.0623$ & $0.1156 \pm 0.0263$ & 0.023 \\
\hline & Subdivision & $0.0801 \pm 0.0314$ & $0.0465 \pm 0.0188$ & 0.039 \\
\hline & Zavarzinella & $0.0741 \pm 0.0238$ & $0.1234 \pm 0.0305$ & 0.009 \\
\hline & Photorhabdus & $0.0013 \pm 0.0029$ & $0.0068 \pm 0.0050$ & 0.023 \\
\hline & Volucribacter & $0.0081 \pm 0.0062$ & $0.0021 \pm 0.0046$ & 0.042 \\
\hline & Blastococcus & $0.0552 \pm 0.0335$ & $0.0144 \pm 0.0145$ & 0.030 \\
\hline & Mesotoga & $0.2509 \pm 0.0703$ & $0.3675 \pm 0.1057$ & 0.039 \\
\hline & Defluviitoga & $0.0550 \pm 0.0252$ & $0.0216 \pm 0.0114$ & 0.030 \\
\hline & Dorea & $0.0063 \pm 0.0065$ & $0.0000 \pm 0.0000$ & 0.025 \\
\hline \multirow[t]{11}{*}{ Species } & Rhodopirellularubra & $0.4011 \pm 0.1433$ & $0.7563 \pm 0.2398$ & 0.013 \\
\hline & Haloferulasargassicola & $0.1534 \pm 0.0629$ & $0.0999 \pm 0.0227$ & 0.030 \\
\hline & Thermogemmatisporafoliorum & $0.7813 \pm 0.2152$ & $1.4957 \pm 0.6735$ & 0.023 \\
\hline & Mycoplasmaequigenitalium & $0.5463 \pm 0.0684$ & $0.6820 \pm 0.1108$ & 0.039 \\
\hline & Bifidobacteriumsubtile & $0.0924 \pm 0.0269$ & $0.2584 \pm 0.1958$ & 0.026 \\
\hline & Natroniellaacetigena & $0.0075 \pm 0.0078$ & $0.0000 \pm 0.0000$ & 0.012 \\
\hline & Flammeovirgakamogawensis & $0.6966 \pm 0.3523$ & $0.2488 \pm 0.1349$ & 0.026 \\
\hline & Eubacteriumyurii & $0.0231 \pm 0.0111$ & $0.0091 \pm 0.0074$ & 0.030 \\
\hline & Enterococcusdiestrammenae & $0.2549 \pm 0.0859$ & $0.1458 \pm 0.0809$ & 0.030 \\
\hline & Pelagicoccusalbus & $0.0127 \pm 0.0057$ & $0.0047 \pm 0.0024$ & 0.017 \\
\hline & Fodinibacterluteus & $0.1588 \pm 0.0461$ & $0.0935 \pm 0.0498$ & 0.039 \\
\hline
\end{tabular}


Table 2 Differential relative abundance of the taxa in ovarian communities between patients in cancer and control group (Continued)

\begin{tabular}{|c|c|c|c|}
\hline & Control cohort $(n=10, \%)$ & Ovarian tumor cohort $(n=6, \%)$ & $P$ value \\
\hline Prosthecobacteralgae & $0.0210 \pm 0.0121$ & $0.0080 \pm 0.0050$ & 0.030 \\
\hline Emticiciaoligotrophica & $0.0743 \pm 0.0297$ & $0.0308 \pm 0.0251$ & 0.013 \\
\hline Leuconostoccitreum & $0.0417 \pm 0.0281$ & $0.0108 \pm 0.0125$ & 0.039 \\
\hline Methanimicrococcusblatticola & $0.2138 \pm 0.0527$ & $0.1572 \pm 0.0383$ & 0.039 \\
\hline Methanosarcinavacuolata & $0.0156 \pm 0.0061$ & $0.0007 \pm 0.0015$ & 0.001 \\
\hline Lactobacillussucicola & $0.0160 \pm 0.0063$ & $0.0081 \pm 0.0053$ & 0.030 \\
\hline Caldicoprobacteroshimai & $0.0014 \pm 0.0041$ & $0.0044 \pm 0.0042$ & 0.048 \\
\hline Caldicellulosiruptorsaccharolyticus & $0.3268 \pm 0.1880$ & $0.1082 \pm 0.1296$ & 0.039 \\
\hline Methylomicrobiumalbum & $0.0013 \pm 0.0021$ & $0.0069 \pm 0.0051$ & 0.013 \\
\hline Novispirillum itersonii & $0.0031 \pm 0.0036$ & $0.0000 \pm 0.0000$ & 0.048 \\
\hline Paenibacillusodorifer & $0.6905 \pm 0.4128$ & $0.2356 \pm 0.1583$ & 0.039 \\
\hline Mycoplasmagenitalium & $0.0023 \pm 0.0038$ & $0.0073 \pm 0.0048$ & 0.043 \\
\hline Sulfurospirillumhalorespirans & $0.0630 \pm 0.0163$ & $0.0948 \pm 0.0306$ & 0.039 \\
\hline Streptococcuscastoreus & $0.0514 \pm 0.0415$ & $0.0190 \pm 0.0329$ & 0.030 \\
\hline Spongiivirgacitrea & $0.2355 \pm 0.1391$ & $0.0921 \pm 0.0784$ & 0.039 \\
\hline Staphylococcuscapitissubsp & $0.0245 \pm 0.0504$ & $0.0752 \pm 0.0506$ & 0.021 \\
\hline Xanthomonasbromi & $0.0094 \pm 0.0117$ & $0.0000 \pm 0.0000$ & 0.025 \\
\hline Vulcanisaeta thermophila & $0.0457 \pm 0.0106$ & $0.0720 \pm 0.0247$ & 0.039 \\
\hline Volucribacter amazonae & $0.0081 \pm 0.0062$ & $0.0021 \pm 0.0046$ & 0.042 \\
\hline Thalassotalea fusca & $0.0316 \pm 0.0202$ & $0.0027 \pm 0.0045$ & 0.004 \\
\hline Thermus islandicus & $0.0051 \pm 0.0049$ & $0.0000 \pm 0.0000$ & 0.025 \\
\hline Prevotella veroralis & $0.0055 \pm 0.0074$ & $0.0000 \pm 0.0000$ & 0.048 \\
\hline Pseudobutyrivibrio xylanivorans & $0.0072 \pm 0.0063$ & $0.0021 \pm 0.0046$ & 0.030 \\
\hline Peptoniphilus methioninivorax & $0.0000 \pm 0.0000$ & $0.0031 \pm 0.0033$ & 0.017 \\
\hline Sphingobacterium arenae & $0.2488 \pm 0.1235$ & $0.0861 \pm 0.0529$ & 0.030 \\
\hline Campylobacter rectus & $0.0050 \pm 0.0064$ & $0.0000 \pm 0.0000$ & 0.048 \\
\hline Blautia glucerasea & $0.0166 \pm 0.0091$ & $0.0056 \pm 0.0067$ & 0.033 \\
\hline Calditerricola yamamurae & $0.0745 \pm 0.0158$ & $0.1084 \pm 0.0306$ & 0.023 \\
\hline Clostridium thermosuccinogenes & $0.0036 \pm 0.0051$ & $0.0127 \pm 0.0089$ & 0.030 \\
\hline Alkalibacillus haloalkaliphilus & $0.0058 \pm 0.0066$ & $0.0000 \pm 0.0000$ & 0.025 \\
\hline Acholeplasma oculi & $0.0038 \pm 0.0041$ & $0.0000 \pm 0.0000$ & 0.025 \\
\hline Aureimonas phyllosphaerae & $0.0013 \pm 0.0029$ & $0.0068 \pm 0.0050$ & 0.023 \\
\hline Azonexus hydrophilus & $0.0773 \pm 0.0316$ & $0.0285 \pm 0.0190$ & 0.007 \\
\hline Anaerostipes rhamnosivorans & $0.0005 \pm 0.0015$ & $0.0045 \pm 0.0043$ & 0.025 \\
\hline Anoxynatronum sibiricum & $0.1172 \pm 0.0708$ & $0.0460 \pm 0.0513$ & 0.034 \\
\hline Legionella taurinensis & $0.0029 \pm 0.0031$ & $0.0000 \pm 0.0000$ & 0.048 \\
\hline Mesonia phycicola & $0.0119 \pm 0.0087$ & $0.0031 \pm 0.0033$ & 0.019 \\
\hline Luteolibacter cuticulihirudinis & $0.2389 \pm 0.1090$ & $0.4292 \pm 0.1517$ & 0.030 \\
\hline Megasphaera indica & $0.0052 \pm 0.0055$ & $0.0000 \pm 0.0000$ & 0.025 \\
\hline Dorea formicigenerans & $0.0063 \pm 0.0065$ & $0.0000 \pm 0.0000$ & 0.025 \\
\hline Fuchsiella alkaliacetigena & $0.0082 \pm 0.0075$ & $0.0014 \pm 0.0031$ & 0.043 \\
\hline Geobacillus thermodenitrificans & $0.0063 \pm 0.0051$ & $0.0006 \pm 0.0013$ & 0.024 \\
\hline
\end{tabular}




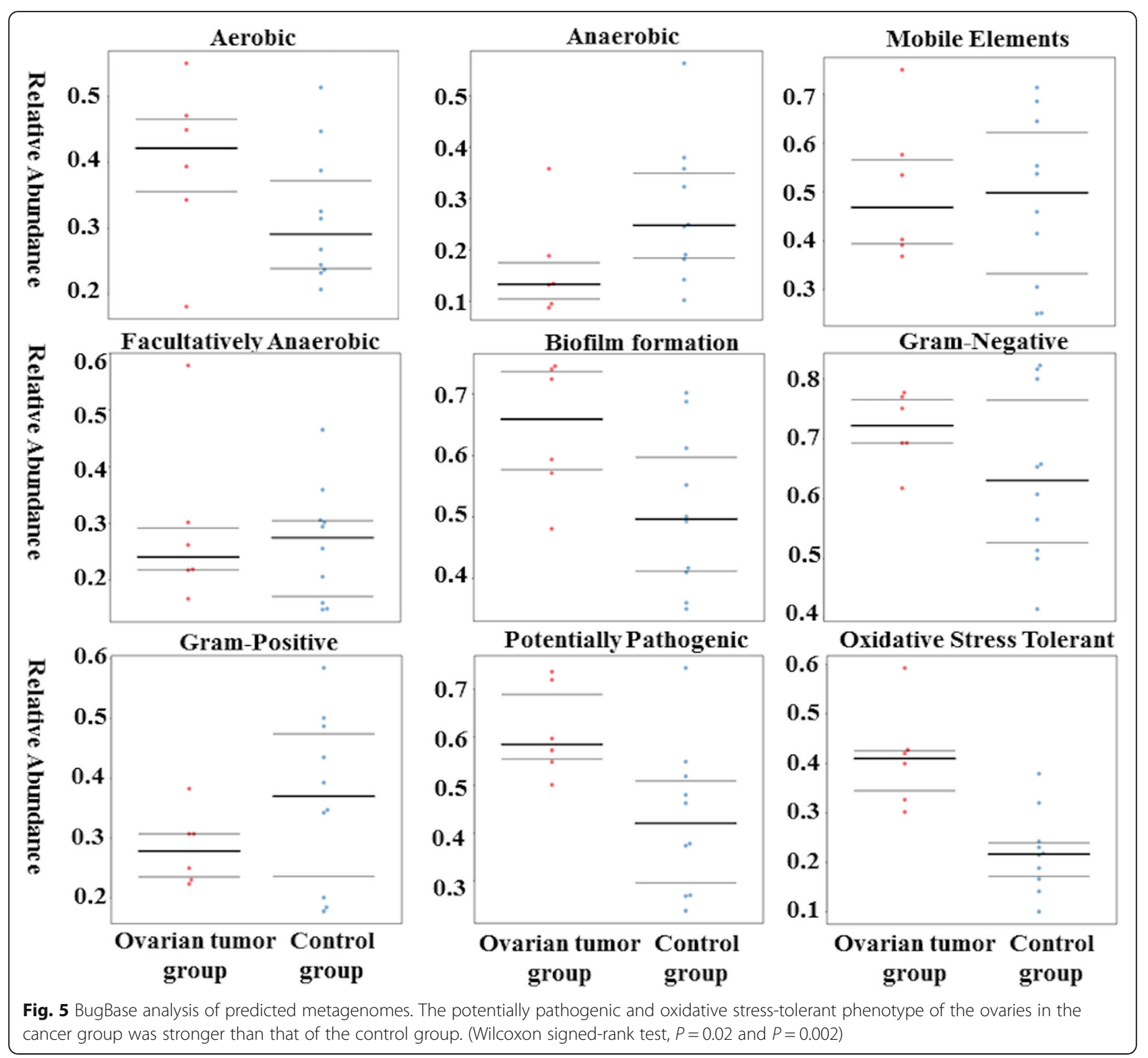

mechanisms that tubal ligation impairs circulation of bacteria that are associated with ovarian cancer risk between the lower and upper genital tract [26]. Second, the bacteria in the upper female reproductive tract, including the ovaries, may be endosymbiotic and separated from other bacteria and the outside environment [4]. Third, we put forward a hypothesis that the blood and abdominal cavity may be the potential source of the ovarian bacteria, and its need further exploration [27].

In this study, we found the presence of bacteria in the ovaries and differences in the ovarian bacteria between patients with ovarian cancer and noncancerous women, which raises further questions that need to be solved. Where did the bacteria originate from? What is the association between the bacteria in the ovaries, uterus, fallopian tubes, vagina, and the outside environment? Are the ovarian bacteria always present? The ovaries are connected and open to the abdominal cavity; did the bacteria transfer from the abdominal cavity and the surface of the organs? Moreover, another doubt is whether the ovarian bacteria is associated with ovulation, ovarian failure, ovarian cysts, polycystic ovarian syndrome and so on. Do the ovarian bacteria drive the occurrence of ovarian cancer or does ovarian cancer change the ovarian bacteria? All the above questions point to the direction of our future research.

Our study first concentrates the research target on the bacteria in the cancerous and normal ovarian tissue. The 


\begin{tabular}{|c|c|c|c|c|c|}
\hline & $95 \%$ confidence intervals & & & \multirow{8}{*}{ 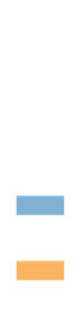 } & \multirow{8}{*}{$\begin{array}{l}\text { Cancer group } \\
\text { Control group }\end{array}$} \\
\hline Streptomycin biosynthesis B & $d$ & \multicolumn{2}{|l|}{$7.85 e-4$} & & \\
\hline Carbon fixation in photosynthetic organisms 日 & d & \multicolumn{2}{|l|}{$8.89 \mathrm{e}-4$} & & \\
\hline Glycosphingolipid biosynthesis - globo series | & 0 & \multicolumn{2}{|l|}{$1.06 \mathrm{e}-3$} & & \\
\hline alpha-Linolenic acid metabolism | & 0 & \multicolumn{2}{|l|}{$1.25 \mathrm{e}-3$} & & \\
\hline Cyanoamino acid metabolism B & $a$ & \multicolumn{2}{|l|}{$1.62 \mathrm{e}-3$} & & \\
\hline Sphingolipid metabolism & a & \multicolumn{2}{|l|}{$1.70 \mathrm{e}-3$} & & \\
\hline Butirosin and neomycin biosynthesis | & d & \multicolumn{2}{|l|}{$2.11 \mathrm{e}-3$} & & \\
\hline Other glycan degradation & $a^{\prime}$ & \multicolumn{3}{|l|}{$2.62 \mathrm{e}-3$} & \\
\hline Biosynthesis of vancomycin group antibiotics | & o & \multicolumn{3}{|l|}{$2.94 \mathrm{e}-3$} & \\
\hline 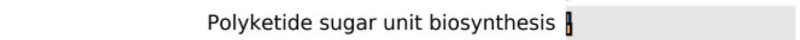 & Q & \multicolumn{3}{|l|}{$3.14 \mathrm{e}-3$} & \\
\hline Biosynthesis of unsaturated fatty acids $\mathrm{日}$ & 10 & \multicolumn{3}{|l|}{$3.16 \mathrm{e}-3$} & \\
\hline Pentose phosphate pathway 日 & $|0|$ & \multicolumn{3}{|l|}{$3.81 \mathrm{e}-3$} & \\
\hline Bacterial secretion system $\overline{\text { 日 }}$ & lol & \multicolumn{3}{|l|}{$4.57 \mathrm{e}-3$} & \\
\hline Proximal tubule bicarbonate reclamation | & 0 & \multicolumn{3}{|l|}{$4.70 \mathrm{e}-3$} & \\
\hline Transporters $\rightleftharpoons$ & $\longmapsto$ & \multicolumn{3}{|l|}{$5.15 \mathrm{e}-3$} & \\
\hline Prion diseases & 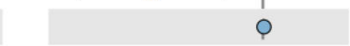 & \multicolumn{3}{|l|}{$5.98 \mathrm{e}-3$} & \\
\hline Secretion system & $1 \longmapsto-1$ & \multicolumn{3}{|l|}{$6.89 \mathrm{e}-3$} & \\
\hline Carbon fixation pathways in prokaryotes & b & \multicolumn{3}{|l|}{$9.49 \mathrm{e}-3$} & \\
\hline Tuberculosis [ & d & \multicolumn{3}{|l|}{$9.50 \mathrm{e}-3$} & \\
\hline Starch and sucrose metabolism 日 & $1-1_{1}^{\prime}$ & \multicolumn{3}{|l|}{0.011} & \\
\hline Fructose and mannose metabolism 日 & म्) & 0.011 & के & & \\
\hline Function unknown & Ito- & 0.011 & 巡 & & \\
\hline Phenylpropanoid biosynthesis & 0 & 0.011 & 岕 & & \\
\hline Lysosome | & $\delta$ & 0.014 & $\underset{\nu}{0}$ & & \\
\hline Other ion-coupled transporters $\square$ & Ino-1 & 0.015 & $\frac{\frac{9}{20}}{\frac{2}{20}}$ & & \\
\hline Sulfur relay system $\bar{\theta}$ & b & 0.019 & à & & \\
\hline Glycosaminoglycan degradation | & 0 & 0.023 & & & \\
\hline 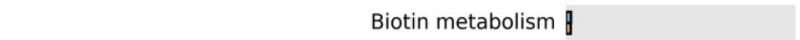 & 0 & 0.024 & & & \\
\hline Pentose and glucuronate interconversions $\mathrm{B}$ & 어 & 0.025 & & & \\
\hline Protein kinases & la & 0.025 & & & \\
\hline Glycosphingolipid biosynthesis - ganglio series | & d & 0.027 & & & \\
\hline Pyruvate metabolism $\boxminus$ & p & 0.027 & & & \\
\hline Amino sugar and nucleotide sugar metabolism & $10-1$ & 0.030 & & & \\
\hline Galactose metabolism $\bar{B}$ & HOH & 0.030 & & & \\
\hline Ubiquinone and other terpenoid-quinone biosynthesis 8 & la & 0.031 & & & \\
\hline Two-component system & $1+\infty$ & 0.032 & & & \\
\hline Folate biosynthesis & b & 0.035 & & & \\
\hline Cell motility and secretion $\bar{\theta}$ & $p$ & 0.035 & & & \\
\hline Citrate cycle (TCA cycle) 日 & a & 0.036 & & & \\
\hline Biosynthesis of ansamycins | & 0 & 0.037 & & & \\
\hline Methane metabolism $\boxminus$ & rot & 0.040 & & & \\
\hline Membrane and intracellular structural molecules $\bar{日}$ & 어 & 0.041 & & & \\
\hline Metabolism of cofactors and vitamins & b & 0.041 & & & \\
\hline Glutamatergic synapse | & Q & 0.045 & & & \\
\hline Cell cycle - Caulobacter 日 & a & 0.045 & & & \\
\hline Ribosome biogenesis in eukaryotes | & 0 & 0.047 & & & \\
\hline 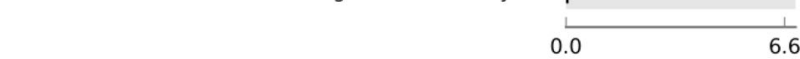 & $\begin{array}{cccc}1 & 1 & 1 & \\
-1.0-0.8-0.6-0.4-0.20 .0 & 0.2 & 0 .\end{array}$ & & & & \\
\hline Mean proportion (\%) & Difference in mean proportions & & & & \\
\hline
\end{tabular}

finding about the presence of bacteria in ovarian tissue might start a new field about the association between bacteria and ovarian cancer. Besides, our result about the compositional and functional difference of bacteria in cancerous and normal ovarian tissue might be a new way to explain the carcinogenesis of ovarian cancer and find the therapeutic and prognostic target of bacteria. However, there are some limitations to our study. The first limitation is that we could not collect the ovaries from healthy patients for ethical reasons. Therefore, we used the noncancerous ovaries from patients with benign uterine disease (including uterine myoma and adenomyosis) as the control group. Another limitation of this study is the small sample size, which may limit further analysis and influence the accuracy of the results. However, it is the preliminary study to detect the 
ovarian bacteria in patients with ovarian cancer, and we will conduct further explorations with larger sample sizes.

\section{Conclusions}

The ovaries contained several kinds of bacteria and were not sterile in a noninflammatory environment. Besides, there were significant differences between the ovarian bacterial compositions of patients in the cancer and control groups.

\section{Abbreviations \\ FFPE: Formalin-fixed paraffin-embedded; IMG4: Integrated Microbial Genomes; KEGG: Kyoto Encyclopedia of Genes and Genomes; LPS: Lipopolysaccharide; OTUs: Operational taxonomic units; PATRIC: Pathosystems Resource Integration Center; PCoA: Principal coordinates analysis; PCR: Polymerase chain reaction; PICRUSt: Phylogenetic Investigation of Communities by Reconstruction of Unobserved States}

\section{Acknowledgements}

We thank the colleagues in the Department of Gynecology of First Affiliated Hospital in Xi'an Jiatong University for their contributions to collecting samples.

\section{Authors' contributions}

WQ: Project development, Data collection, Data analysis, Manuscript writing ZL, HL, TX, MS and LQ: Data collection. WY and LD: Data analysis and data collection. TM and SC: Project development. FG and WQing: Project development and data analysis. SQ and LQL: Experimental design and project development. All authors read and approved the final manuscript.

\section{Funding}

This work was supported by grants from the Fundamental Research Funds for Xi'an Jiaotong University (xjj2015093), and Major Basic Research Project of Natural Science of Shaanxi Provincial Science and Technology Department (2017ZDJC-11), the Key Research and Development Project of Shaanxi Provincial Science and Technology Department (2017ZDXM-SF-068), and Shaanxi Provincial Collaborative Technology Innovation Project (2017XT-026, 2018XT-002). The funders had no role in study design, data collection and analysis, decision to publish, or preparation of the manuscript.

\section{Availability of data and materials}

Please contact the corresponding author Qiling Li (liqiling@mail.xjtu.edu.cn).

\section{Ethics approval and consent to participate}

This study was approved by the Medical Institutional Ethics Committee of the First Affiliated Hospital of Xi'an Jiaotong University. Informed consent was obtained from all the enrolled patients.

\section{Consent for publication}

Not applicable.

\section{Competing interests}

The authors declare that they have no competing interests.

\section{Author details}

'Department of Obstetrics and Gynecology, First Affiliated Hospital, Xi'an Jiaotong University, Xi'an, Shaanxi, China. ${ }^{2}$ Department of Gynecological Oncology, Shaanxi Provincial Cancer Hospital, Xi'an, Shaanxi, China. ${ }^{3}$ Guipei 77, Health Science Center, Xi'an Jiaotong University, Xi'an, Shaanxi, China. ${ }^{4}$ Omega Bioservices Inc, Norcross, GA, USA. ${ }^{5}$ Cardiovascular Research Institute, Morehouse School of Medicine, Atlanta, Georgia, USA.
Received: 5 October 2019 Accepted: 17 December 2019

Published online: 18 January 2020

\section{References}

1. Geller LT, Barzily-Rokni M, Danino T, Jonas OH, Shental N, Nejman D, et al. Potential role of intratumor bacteria in mediating tumor resistance to the chemotherapeutic drug gemcitabine. Science. 2017:357(6356):1156-60.

2. Manfredo Vieira S, Hiltensperger M, Kumar V, Zegarra-Ruiz D, Dehner C, Khan N, et al. Translocation of a gut pathobiont drives autoimmunity in mice and humans. Science. 2018;359(6380):1156-61.

3. Brunelli R, Papi M, Arcovito G, Bompiani A, Castagnola M, Parasassi T, et al. Globular structure of human ovulatory cervical mucus. FASEB J. 2007;21(14): 3872-6.

4. Chen C, Song X, Wei W, Zhong H, Dai J, Lan Z, et al. The microbiota continuum along the female reproductive tract and its relation to uterinerelated diseases. Nat Commun. 2017;8(1):875.

5. Zervomanolakis I, Ott HW, Hadziomerovic D, Mattle V, Seeber BE, Virgolini I, et al. Physiology of upward transport in the human female genital tract. Ann N Y Acad Sci. 2007;1101:1-20.

6. Verstraelen $H$, Vilchez-Vargas $R$, Desimpel $F$, Jauregui $R$, Vankeirsbilck $N$, Weyers $\mathrm{S}$, et al. Characterisation of the human uterine microbiome in nonpregnant women through deep sequencing of the $\mathrm{V} 1-2$ region of the $16 \mathrm{~S}$ rRNA gene. PeerJ. 2016;4:e1602

7. Fang RL, Chen LX, Shu WS, Yao SZ, Wang SW, Chen YQ. Barcoded sequencing reveals diverse intrauterine microbiomes in patients suffering with endometrial polyps. Am J Transl Res. 2016;8(3):1581-92.

8. Miles SM, Hardy BL, Merrell DS. Investigation of the microbiota of the reproductive tract in women undergoing a total hysterectomy and bilateral salpingo-oopherectomy. Fertil Steril. 2017;107(3):813-20 e1.

9. Kostic AD, Gevers D, Pedamallu CS, Michaud M, Duke F, Earl AM, et al. Genomic analysis identifies association of Fusobacterium with colorectal carcinoma. Genome Res. 2012;22(2):292-8.

10. Bullman S, Pedamallu CS, Sicinska E, Clancy TE, Zhang X, Cai D, et al. Analysis of Fusobacterium persistence and antibiotic response in colorectal cancer. Science. 2017:358(6369):1443.

11. Wang L, Zhou J, Xin Y, Geng C, Tian Z, Yu X, et al. Bacterial overgrowth and diversification of microbiota in gastric cancer. Eur J Gastroenterol Hepatol. 2016;28(3):261-6.

12. Hosgood HD 3rd, Sapkota AR, Rothman N, Rohan T, Hu W, Xu J, et al. The potential role of lung microbiota in lung cancer attributed to household coal burning exposures. Environ Mol Mutagen. 2014:55(8):643-51.

13. Kwon M, Seo SS, Kim MK, Lee DO, Lim MC. Compositional and Functional Differences between Microbiota and Cervical Carcinogenesis as Identified by Shotgun Metagenomic Sequencing. Cancers. 2019;11(3):309.

14. Urbaniak C, Gloor GB, Brackstone M, Scott L, Tangney M, Reid G. The microbiota of breast tissue and its association with breast Cancer. Appl Environ Microbiol. 2016;82(16):5039-48.

15. Feng $Y$, Ramnarine VR, Bell R, Volik S, Davicioni E, Hayes VM, et al. Metagenomic and metatranscriptomic analysis of human prostate microbiota from patients with prostate cancer. BMC Genomics. 2019;20(1):146.

16. Bolger AM, Lohse $M$, Usadel B. Trimmomatic: a flexible trimmer for Illumina sequence data. Bioinformatics. 2014:30(15):2114-20.

17. Kanehisa M, Goto S, Sato Y, Furumichi M, Tanabe M. KEGG for integration and interpretation of large-scale molecular data sets; 2012

18. Markowitz VM, Chen IM, Palaniappan K, Chu K, Szeto E, Grechkin Y, et al. IMG: the integrated microbial genomes database and comparative analysis system. Nucleic Acids Res. 2012;40(Database issue):115-22.

19. Snyder EE, Kampanya N, Lu J, Nordberg EK, Karur HR, Shukla M, et al. PATRIC: the VBI PathoSystems resource integration center. Nucleic Acids Res. 2007:35(Database issue):D401-D6.

20. Langille MGl, Zaneveld J, Caporaso JG, Mcdonald D, Dan K, Reyes JA, et al. Predictive functional profiling of microbial communities using 165 rRNA marker gene sequences. Nat Biotechnol. 2013;31(9):814.

21. Parks DH, Tyson GW, Hugenholtz P, Beiko RG. STAMP: statistical analysis of taxonomic and functional profiles. Bioinformatics. 2014;30(21):3123.

22. Leranth C, Hamori J. "Dark" Purkinje cells of the cerebellar cortex. Acta Biol Acad Sci Hung. 1970;21(4):405-19.

23. Walther-Antonio MR, Chen J, Multinu F, Hokenstad A, Distad TJ, Cheek EH, et al. Potential contribution of the uterine microbiome in the development of endometrial cancer. Genome Med. 2016;8(1):122. 
24. Sieh W, Salvador S, McGuire V, Weber RP, Terry KL, Rossing MA, et al. Tubal ligation and risk of ovarian cancer subtypes: a pooled analysis of casecontrol studies. Int J Epidemiol. 2013;42(2):579-89.

25. Rice MS, Hankinson SE, Tworoger SS. Tubal ligation, hysterectomy, unilateral oophorectomy, and risk of ovarian cancer in the Nurses' health studies. Fertil Steril. 2014;102(1):192-8 e3.

26. Mert I, Walther-Antonio M, Mariani A. Case for a role of the microbiome in gynecologic cancers: Clinician's perspective. J Obstet Gynaecol Res. 2018; 44(9):1693-704.

27. Paisse S, Valle C, Servant F, Courtney M, Burcelin R, Amar J, et al. Comprehensive description of blood microbiome from healthy donors assessed by $16 \mathrm{~S}$ targeted metagenomic sequencing. Transfusion. 2016;56(5): 1138-47.

\section{Publisher's Note}

Springer Nature remains neutral with regard to jurisdictional claims in published maps and institutional affiliations.

Ready to submit your research? Choose BMC and benefit from:

- fast, convenient online submission

- thorough peer review by experienced researchers in your field

- rapid publication on acceptance

- support for research data, including large and complex data types

- gold Open Access which fosters wider collaboration and increased citations

- maximum visibility for your research: over $100 \mathrm{M}$ website views per year

At BMC, research is always in progress.

Learn more biomedcentral.com/submissions 